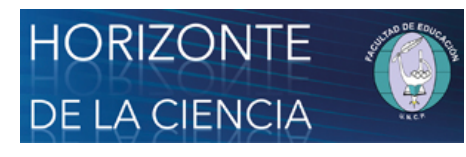

Horizonte de la Ciencia

ISSN: 2413-936X

horizontedelaciencia@uncp.edu.pe

Universidad Nacional del Centro del Perú

Perú

\title{
Desafíos del Posgrado Peruano: Internacionalización y evaluación externa
}

\author{
Yangali Vargas, Jorge \\ Desafíos del Posgrado Peruano: Internacionalización y evaluación externa \\ Horizonte de la Ciencia, vol. 10, núm. 18, 2020 \\ Universidad Nacional del Centro del Perú, Perú \\ DOI: https://doi.org/10.26490/uncp.horizonteciencia.2020.18.411
}

Los autores otorgan el permiso a compartir y usar su trabajo manteniendo la autoría del mismo. Atribución no comercial (CC BY-NC) 4.0 


\title{
Desafíos del Posgrado Peruano: Internacionalización y evaluación externa
}

\author{
Jorge Yangali Vargas \\ Universidad Nacional del Centro del Perú, Perú \\ jyangali@uncp.edu.pe \\ (iD) http://orcid.org/0000-0003-3714-326X
}

DOI: https://doi.org/10.26490/

uncp.horizonteciencia.2020.18.411

Palabras Clave: Posgrados, Movilización, Internacionalización, Evaluación externa

El sistema de educación superior peruano viene implementando mecanismos que le aseguren a la ciudadanía contar con un servicio de calidad. En diciembre de 2019 culmina el plazo para que las universidades cuenten con el licenciamiento (Sunedu). Licencia que confirma que el servicio que prestan es el que declaran en su oferta académica. Tanto universidades públicas como privadas han realizado denodados esfuerzos además invertido ingentes recursos para alcanzar el licenciamiento de sus programas de pregrado y posgrado.

Si bien en el pregrado se han efectivizado los convenios y con éstos los sistemas de becas que permiten el flujo de estudiantes nacionales y extranjeros de otras universidades mediante el sistema de movilidad estudiantil; el posgrado aún está rezagado al respecto. Muchos son los motivos por los que los estudiantes (en especial los nacionales) de posgrado no se movilizan. Algunos motivos serían: los posgrados peruanos no son gratuitos -ni en las universidades públicas - y los costos entre universidad y universidad varían significativamente. De concretarse la movilidad los posgrados tendrían que aceptar que el estudiante continúe abonando el mismo monto que en su universidad de procedencia (Gestión 2018).

Otra de las razones tiene que ver con la carencia de una política de becas de manutención que estimule el intercambio, dejando al estudiante la carga económica tanto de las pensiones de enseñanza como de su propio sustento. Se sobrentiende que estudiar un posgrado implica asumir una carga laboral (o recibir el apoyo familiar) que permita cubrir sus costos. Otra razón importante que frena la movilidad estudiantil a nivel de posgrado son las mallas curriculares rígidas de la mayor parte de los programas en especial de las universidades públicas; lo cual dificulta las convalidaciones.

Este contexto no favorece el producto esperado de los posgrados y más bien los precariza: las tesis o informes de investigación. Si bien desde Concytec (2019) se tiene el deseo de incrementar el volumen de investigadores y por ende de publicaciones en el sistema universitario peruano, esto no se puede lograr si se sigue mirando de soslayo los posgrados nacionales y favoreciendo la movilización y becas sólo hacia el exterior. Cambiar esta realidad implicaría, por ejemplo, conceder becas tanto a connacionales como a extranjeros para que estudien cuando menos un semestre en algún programa de posgrado peruano con la totalidad de costos financiados. Exigiéndole al becario, en contraparte, la dedicación exclusiva a la labor de investigación.

Otra de las funciones en las que las escuelas y unidades de posgrado tienen que concentrarse es en la de crear redes que favorezcan la evaluación externa y especializada de las tesis[1]. Lo cual conllevaría a crear un sistema de certificación profesional que asegure la idoneidad del académico (docente de posgrado) para que asuma el rol de asesor y/o jurado de tesis externo, de trabajos de investigación cuya línea es de su dominio.

La experiencia que venimos adquiriendo las revistas para comprometer a nuestros evaluadores pares (todos externos a nuestra institución) tiene que ser aprovechada por los administradores de los posgrados para

NotAS DE AUTOR

jyangali@uncp.edu.pe 
tejer una red de académicos que contribuyan al desarrollo de sus áreas (científicas o humanas) en especifico. Internacionalizar implica abrir los posgrados tanto a la movilidad como a la evaluación externa. Lo cual es un reto de urgente implementación en los posgrados peruanos.

\section{REFERENCIAS BIBLIOGRÁFICAS}

Fondecyt (2019) Becas/Movilizaciones. http://www.cienciactiva.gob.pe/

Gestión (2018) Estas son las maestrías más solicitadas y sus costos en las principales universidades. https://gestion.pe/ economia/management-empleo/son-maestrias-solicitadas-peru-costos-249579-noticia/

López, C. F. y otros (2019) Red de investigación de posgrado en educación creación y perspectivas. Huancayo: UNCP/ UNE/UNDAC/UNHEVAL/UNH/UNSCH

Sunedu (2019) Avances y estatus de Licenciamiento. https://www.sunedu.gob.pe/avances-licenciamiento/

\section{Notas}

[1] Un modelo de red, sería el que se viene gestando entre las conformantes de la Red de Investigación de Posgrados en Investigación (RIPE, véase el informe de López 2019).

Los autores otorgan el permiso a compartir y usar su trabajo manteniendo la autoría del mismo.

CC BY-NC 